\section{A Case of Non-Insulin-Dependent Diabetes Mellitus Asso- ciated with Anorexia Nervosa}

It is well known that insulin-dependent diabetes mellitus (IDDM) is frequently associated with eating disorders, which may cause therapeutic problems $(1,2)$. Here we describe a case of non-insulin-dependent diabetes mellitus (NIDDM) associated with anorexia nervosa.

A 24-year-old woman was diagnosed to have NIDDM at 18 years of age and was started on insulin therapy (up to 34 units/day). Although the glycemic control had been fair for about one year (HbAlc 5.1\%), it became gradually worse ( $\mathrm{HbAlc}$ increased to $12.7 \%$ ). The patient was admitted because of diabetic ketoacidosis in February 1995. Her urinary C-peptide secretion was $27.6 \mu \mathrm{g} /$ day. After the glycemic control was improved again (HbAlc $4.7 \%$ with 14 units/day of insulin) in April 1995, both the patient and her family were given instructions on diet therapy for diabetes mellitus. Thereafter she gradually developed a loss of appetite and began to complain of both a fear of gaining body weight and a guilty feeling about poor intake. Her body weight fell to $37 \mathrm{~kg}$ ( $8 \mathrm{~kg}$ loss) with amenorrhea. Blood glucose was decreased, making insulin therapy unnecessary (HbAlc 5.7\%). She was admitted to the Department of Psychiatry under the diagnosis of anorexia nervosa. Psychotherapy including education of her mother was performed with the cooperation of psychiatrists, endocrinologists and nurses as a team, and at the same time the patient was told to feel free to eat as much as she could. Thereafter both her mental and metabolic conditions were stabilized for several months, and the patient began to gain body weight. However, when her body weight reached $55 \mathrm{~kg}$, her glycemic control became suddenly poor again (HbAlc 7.4\%), necessitating an oral hypoglycemic agent (glibenclamide up to $5.0 \mathrm{mg} / \mathrm{day}$ ). She has had no episode of bulimia to date.

Although it has been known that the association of eating disorders occurs frequently in IDDM, which may lead to poor glycemic control of IDDM, Steel et al reported that metabolic control of IDDM did not deteriorate after the onset of eating disorders (2). A recent preliminary report has suggested that subclinical eating disorders may also be relatively common among patients with $\operatorname{NIDDM}(3)$. The present case suggests that the development of eating disorders should also be considered in the treatment of subjects with NIDDM, especially in young female patients. The association of the two diseases provokes a therapeutic dilemma because the principles of diet therapy are totally different between the two disorders. Although the team care worked transiently to control the two disorders in the present case, constant control seemed to hard to obtain in general.

\section{Megumi Aizawa, Hiromi SaKaguchi, Yasutomo Fukunaga, Cho Ashida and Hiroyuki Koshiyama}

The Division of Endocrinology and Metabolism, Department of Internal Medicine, Hyogo Prefectural Amagasaki Hospital, Amagasaki, Hyogo 660 Reprint requests should be addressed to Dr. Hiroyuki Koshiyama, the Division of Endocrinology and Metabolism, Department of Internal Medicine, Hyogo Prefectural Amagasaki Hospital, Amagasaki, Hyogo 660

\section{References}

1) Jacobson AM, Hauser ST, Anderson BJ, Polonsky W. Psychosocial aspects of diabetes. In: Joslin's Diabetes Mellitus, 13th ed., Kahn CR, Weir GC, Eds. Lea \& Febiger, Philadelphia, 1994, p. 431.

2) Steel JM, Young RJ, Lloyd GG, Clarke BF. Clinically apparent eating disorders in young diabetic women: associations with painful neuropathy and other complications. Br Med J (Clin Res Ed) 294: 859, 1987.

3) Mannuchi E, Bardini G, Ricca V, Rotella CM. Eating attitudes in patients with non insulin dependent diabetes mellitus (NIDDM). Abstracts of 10th International Congress of Endocrinology, San Francisco, p. 978, 1996. 